\title{
STUDIES ON CONVENTIONAL PRODUCTION BY BIONIC STRUCTURES
}

\author{
Vikky Chobey \\ Department of Automobile Engineering \\ Chandigarh university, Mohali, Punjab, India \\ Mihir \\ Department of Automobile Engineering \\ Chandigarh university, Mohali, Punjab, India
}

\begin{abstract}
Any manufacturing unit or design engineer is not perfect as living creatures, which get evolution in the nature. There are many impulsive enhancements in the technocrat world of engineers, and hence searching for optimal solutions. The learnings from the technology of natural surroundings is gaining more appreciation because natural created organisms have mechanisms which have zero failure and economical too. The path of results formed by surroundings of nature and engineers mind developed technique in particular portfolio is defined as "Conventional production by bionic structure". In this study the experimentation of bionic structure design, processes involved in production and applications area of bionic successes in practical area are elaborated.
\end{abstract}

Keywords - Nature, bionic, mythology of bionic, structure

\section{INTRODUCTION}

A very long period of time the nature developed some biological structure with outstanding properties and creative frames, that biological structure provides us a way to solve engineering problem and also design some new thing that inspired by the natural integrity. Here the terms come that we called "bionic" a structure that inspired by the natures, it formed by two Greek words Bion that means 'natures' and suffix 'ic' which means 'like or inspired [1-3].

Bionic is searching for application of biological structures and information in machine design, architectures, and various other engineering and normal problems. Its combined technology as well as bio to achieve goal that is solution. The bionic structures widely used in various fields like architectures, machine constructions, robotics, elections, automobiles, micro, nano science and technology, aviation, space, energy production, domestic industries. So the bionic used in almost all field its make impact on all fields of research as shown in Fig 1.

The paper will show how bionics has been used for the development of resource and energy efficient solutions for machine tools and production technology. In the first part of the paper, bionics in daily human life and its industrial

\author{
Supreet Singh \\ Department of Mechanical engineering \\ Chandigarh university, Mohali, Punjab, India \\ Yogesh Chaudhary \\ Department of Automobile Engineering \\ Chandigarh university, Mohali, Punjab, India
}

application. The second part is attentive on Methodology of bionic design. Here method of designing a bionic structure of any part that how to approach for a bionic structure. In the last part of the paper, the use of bionic structure in architecture and how the bionic provide a strength and protection on various prospective like air control, weight saving and another thing like that [4].

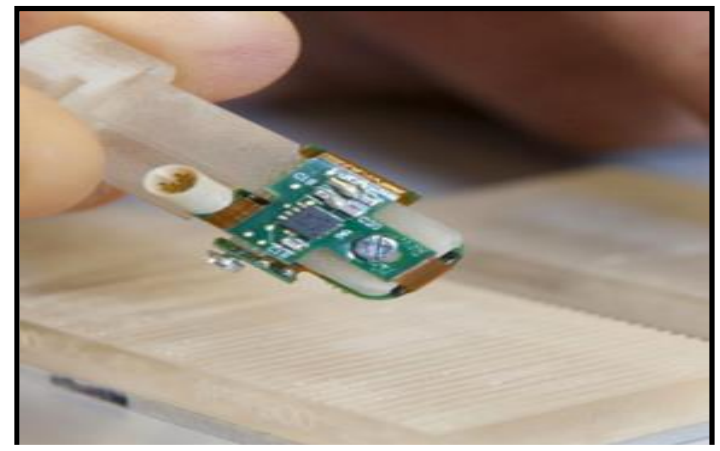

Fig 1: Electrical sensor for Finger print using bionic design [5]

Nature having of the solution of all problems but humans having that type of minds to solve the problem. Some of the major problem that humans faced and solved by using natures-

\section{A. Robotics}

In robotics the technology of bionic used form a very long time some prostatic legs, hand even some developer also working on the bionic eye that give some humans a live those lost some body parts in accidents. Various researchers of computer and electrical engineering at the University of Texas at Austin made an electronic tongue that can help some food companies to create some new tastes, that device sensor work like real tongue. Companies are developing some tiny and big robotic animal like spider, kangaroo, bull any many more that inspired by the real working of their originals. Fig 2 depict Fig. 3 illustrate 


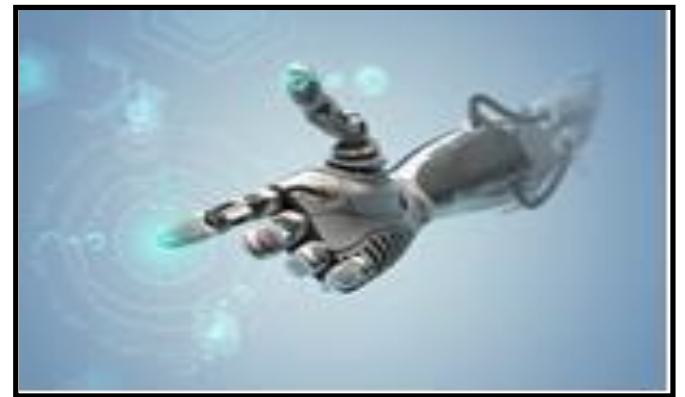

Fig: 2 Bionic prosthetic sensory robotic arm [6]

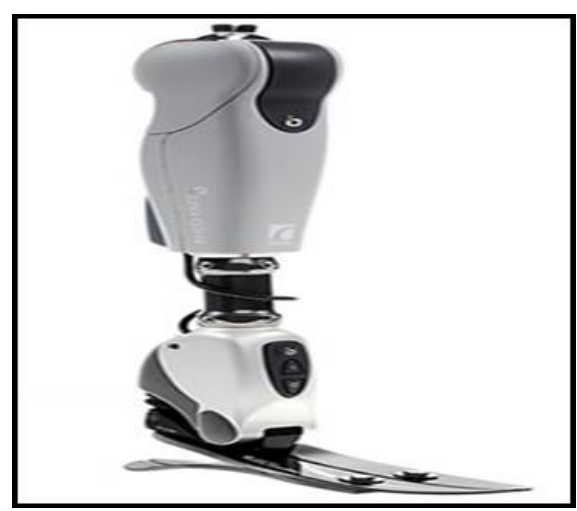

Fig: 3 Bionic prosthetic sensory robotic leg [7]

\section{B. Aviation and Automobiles}

The hole of idea of aviation was derived by the birds, structure of airplane also inspired by the birds the airbus working of a model that replica of bird's internal structures its having equal strength but less material used to make it. Some cars which having very good aerodynamic that totally inspired by the nature. high speed bullet trains need so less air resistance to order to provide them the shape of the face of the trains copy by the bird's beak as shown in Fig. 4 and 5 [8].

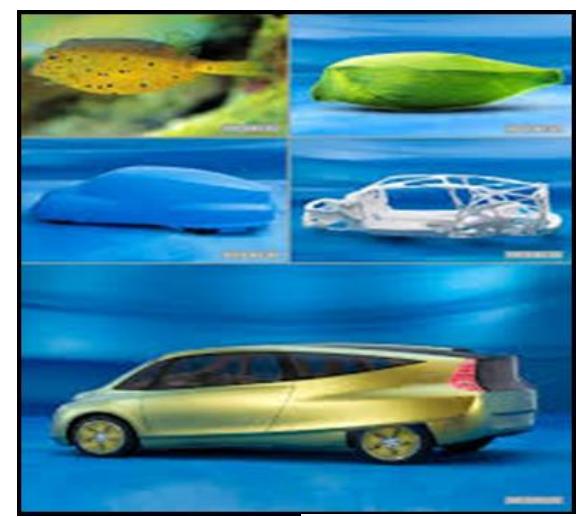

Fig: 4 Bionic cars by Mercedes-Benzes [9]

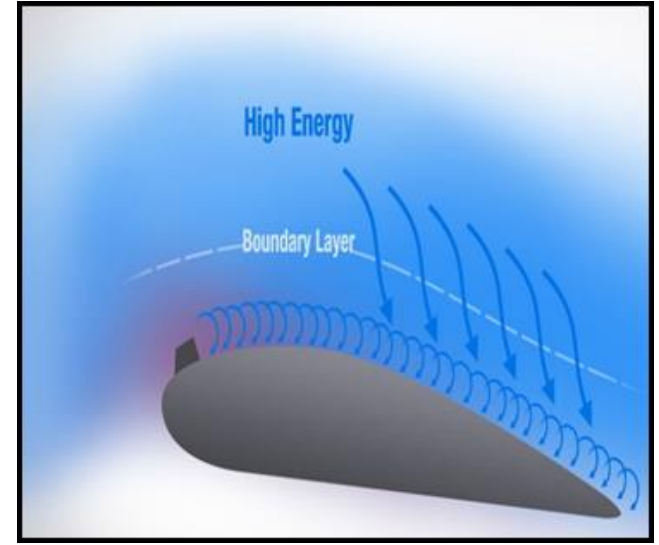

Fig: 5 Wing with vortex generators [9]

\section{Electrical and Electronics}

The wing structure of butterflies has also inspired the creation of new Nano sensors to detect explosives. The neon sensors inspired by the wing structure butterfly. At present the apples phones comes with that types of neon chips which having less in the size efficient in work and also less power consuming as shown in Fig.6.

The various systems of 'Eco-Cyborg' classification of bionic method include the fusion of ordinary environmental procedures to technocrats through animal husbandry ecological functions. Further this caused the formation of a self-driven automatic or the hybrid system. The construction and energy mechanism ecosystems as being similar to flow of energy among components though power circuit.

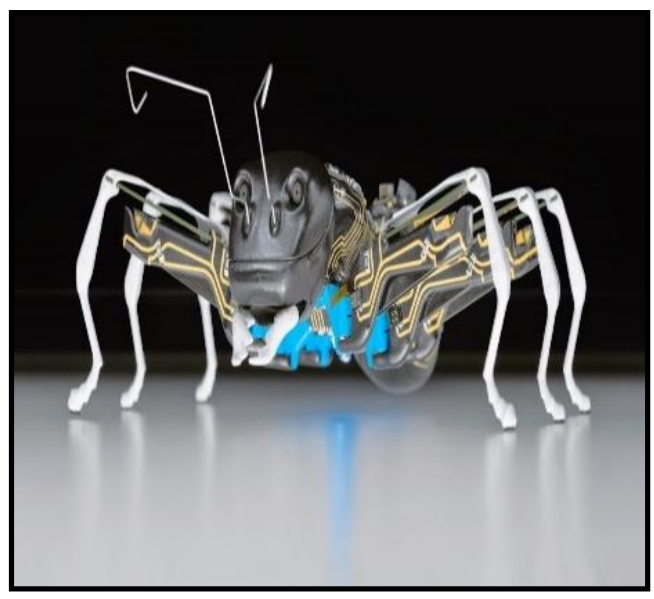

Fig: 6 A spy ant bot fabricated with the help of bionic [10] 


\section{International Journal of Engineering Applied Sciences and Technology, 2020 \\ Vol. 4, Issue 12, ISSN No. 2455-2143, Pages 193-198 \\ Published Online April 2020 in IJEAST (http://www.ijeast.com)}

\section{Architectural Application areas}

In architecture the nature plays an important to make them strong, good looking and help us to solve faced problem with the help of technology. There is some example of bionic structure:

(i) Bionic Tower China: the constriction of this tower stated in 1997 that tower having everything that needed by the people, it is a vertical city and an eco-city that having all needed things. The design of this Skyscraper inspired by three thing of nature first is vegetable that grow higher than other that plant around it help to find a solution for requirement of living vertically because of absence of space and land. Second is the shape of bird's egg that strong but powerful, available and look like giant capsule this help the air movement in and out of the tower and offer sufficiently of light, the third is large trees root system that help to provide floating anti earthquake foundation as shown in Fig. 7 (a). [11].

(ii) Turning Torso, Sweden: It is the second tallest resistance complex. It contains offices, apartment, and conference room that having a beautiful architecture that having nine turning cubes. Key encouragement for designing of this building was a turning human symbol which was adapted in building as nine turning cubes as shown in Fig. 7 (b). [12].

(iii) Tree Scraper Tower of Tomorrow: The focal muse of this building was the growth pattern of tree, natural shape of tree main muse. In building this structure unconditional smallest row materials have been used and air movement was maximized by use of round corners as shown in Fig. 7 (c). [11].

(iv) Selfridge Building, Birmingham: A shields named PAKORABANE which is made from interlocking chains. The foremost feature of that building that because of this structure is forward movement in exterior of structure. The owner of building wanted a very unique and attractive building and by applying Bionic architecture rules such building can be very different and attractive yet functional as shown in Fig. 7 (d). [12].

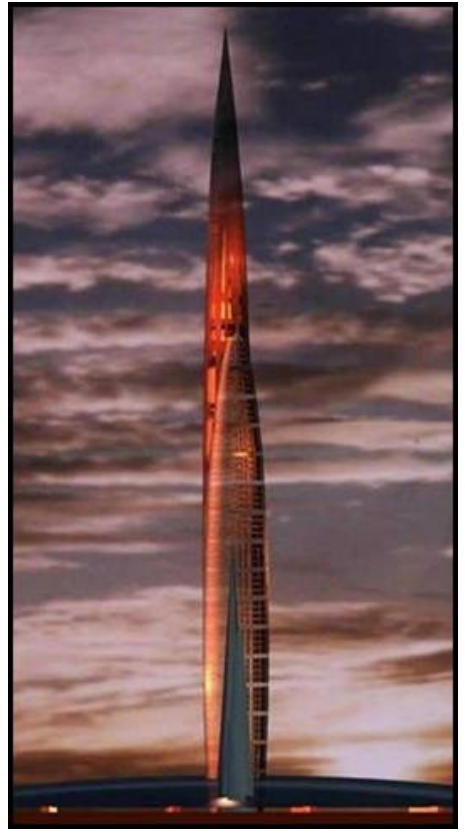

Fig.7:(a) Bionic tower, china [13]

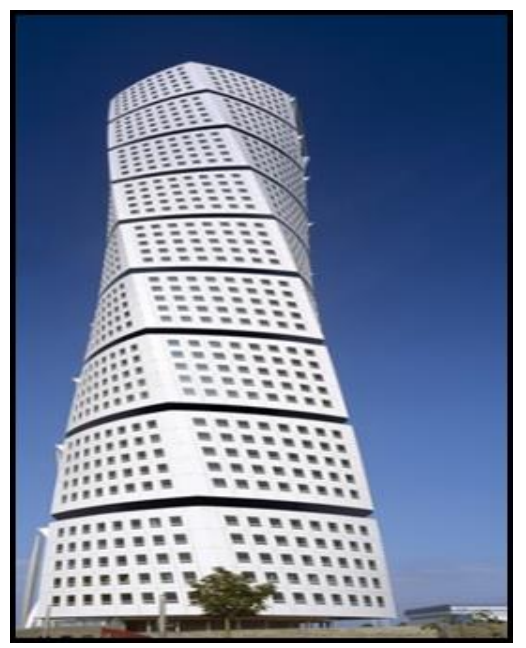

Fig.7: (b)Turning Torso, Sweden [12] 


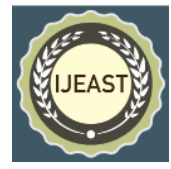

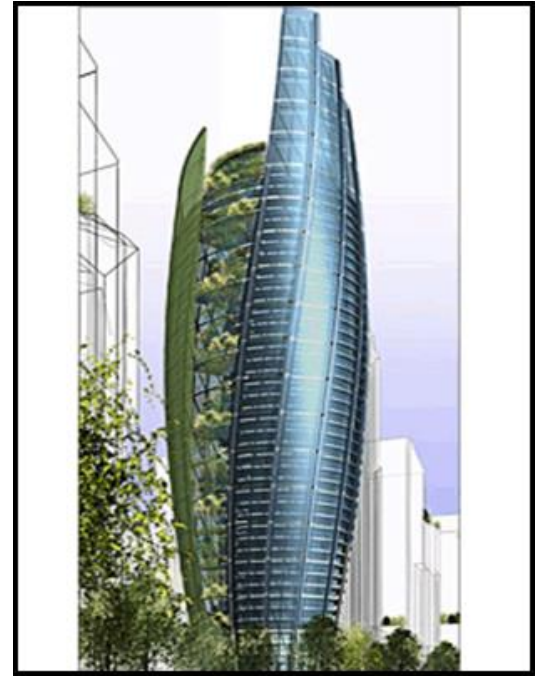

Fig 7: (c)Tree Scraper Tower of Tomorrow [12]

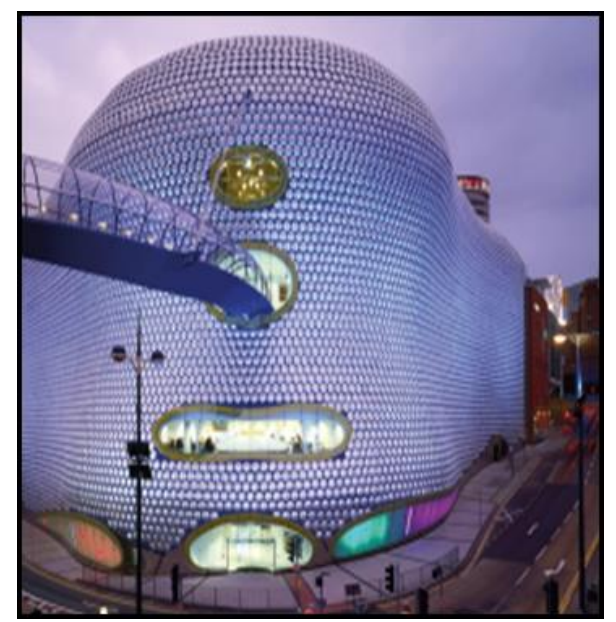

Fig 7: (d) Selfridge Building, Birmingham [12]

\section{METHODOLOGY OF BIONIC DESIGN}

Right in details and general methodology of getting moved from one position to another answer from the nature to way of doing has not been working out still. It is a question if it is possible at all, because to work out such a general methodology acting without feeling of engineers is not possible on this stage of bionic development. It outcome from the fact that in each person Case there are different tasks to get answer to and different events for mathematical designing to be copied and based on experience act of making certain of. On base of made public papers it is possible to put clearly the general steps in bionic designing new ends or working out the new processes [13].
In biological given impulse to process or purpose development it is possible to see what is different 2 general examples.

A. The special to some science or trade hard question is formed and makes observations are looking for its best selection answer in natural everything nearby.

B. In the natural everything nearby the interesting processes, material, plants or animals structure was taken to be and persons making observations are looking for best selection special to some science or trade application The written works paper make clear that Case A " is more frequent in do. From written works paper results that biologically given impulse to special to some science or trade hard question answer can be done in the coming here-after stages

1. Special to some science or trade purpose rules to make.

2. Biological structures, materials or processes observations in order to get out biological scaled-copy for special to some science or trade hard question getting answer to, way out of and first put value of this scaled-copy.

3. Mathematical designing to be copied of machine-like structure or process on the base of biological good example; here very often with limits part careful way is sent in name for.

4. Taking into account the results of designing to be copied the material scaled-copy of the purpose or test support for process observations is made come into existence.

5. Based on experience observations of the material scaledcopy (stiffness, conditions making things hard and twisting distribution, weight, tiredness resistance, damage stopping effect) or process (relation between input and out-put parameters) are doing.

6. On the base of experiments from point No 5 usually it is possible to value bionic design to be copied of the purpose or process and put forward, into use way of putting right or building first working design of the purpose or process. It is value to underline that the very important operation of making observations apparatus for making or put right things in above presented methodology is feeling [14].

\section{MANUFACTURING METHOD OF MECHANICAL BIONIC COMPONENTS}

To make a nature inspired mechanical components industries can't choose the traditional method of manufacturing like casting, coating, molding, forming etc. because that method cannot provide an economical product and also that components having more complexity that can't produce by that methods. That's why industries using additive manufacturing techniques that play an imported role to develop a mechanical product [15].

Three steps which are broadly classified for manufacturing are as follows:

1) Construction morphological elements 


\section{International Journal of Engineering Applied Sciences and Technology, 2020 \\ Vol. 4, Issue 12, ISSN No. 2455-2143, Pages 193-198 \\ Published Online April 2020 in IJEAST (http://www.ijeast.com)}

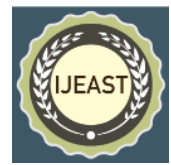

2) Materials and constructions and

3) Biological overview photographs.in that categories, several styles to adapt a bionic design with technical system are analyzed. The bionic design not only considers connections, joints and mechanisms, but also considers biological lubricants or gripping structures for the material arrangement and lightweight design [15].

Considering mansion characteristics, the arrangement of material that inspired by nature for a lightweight design achieved by using SLM is taken in to use.

A. Selective Laser Melting: The SLM process has identified the product as being formed by selecting the succession of power layers via a laser beam. Selective laser melting (SLMs) is one of the latest manufacturing additives developed in the late 1980 and 90s. When preserved, the powder material is heated and melts and forms a liquid pool and adequate energy is applied. Then the molten pool rapidly solidifies and cools down, and the item begins to form the mixed material. After scanning the sample of a layer, the structure platform will be reduced by a quantity equivalent to the density of the layer and a fresh powder layer will be laid [16].

It is repeated until the product is finished. This layer by layer procedure was initially used to produce prototypes, but due to its ability to produce complex structures from a CAD model and a wide range of materials without the need for expensive machining, it tends towards direct manufacture of components, to minimize the delay between construction and production process. Furthermore, the powder only melts locally through the laser and the remaining powder can be recycled for further manufacturing. Due to the advantages of conventional training techniques [17], the process increases the number of components in the automotive, biomedical, aircraft, energy and other industries. Industry 4.0 plays a critical and important role in the cost-efficient Internet of Things in different industrial applications. In recent years, many alloys have improved [15], such as stainless steel, titanium, aluminum, and nickel-based alloy.

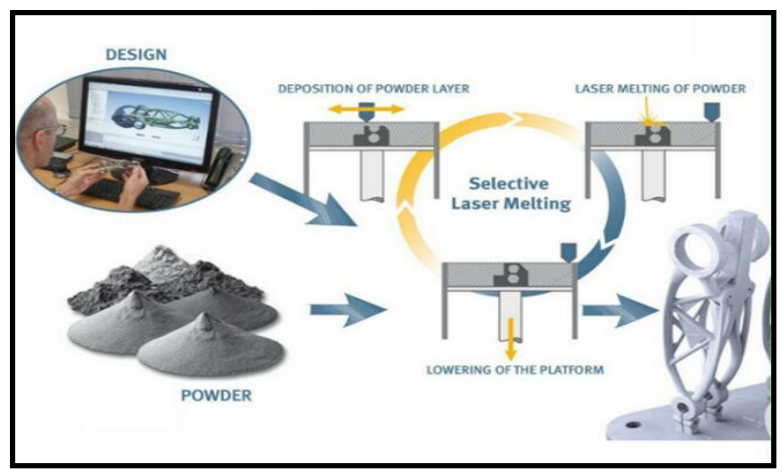

Fig.8: Selective Laser Melting process [13] (i)

The production process is very flexible and suitable for product with less product life cycle.

There is practically no limit on the shape of the product, and parts such as hollows and three dimensional nets can be produced.

Reduced the cost of the manufacturing of per part and

also time saving

pe product quality is better, and the mechanical load performance can be compared with the traditional production technology (such as forging, etc.) [15].

\section{Disadvantages of SLM:}

(i) The mechanism of this process is quite costly.

(ii) Not suitable for very large companies.

(iii) Difficult to maintain. [15]

(iv) Not suitable for valuable assets like land building.

\section{CONCLUSIONS}

The bionic design is very useful for different-different field like architecture, robotics, automobile, aviation and other differ fields. In this paper shown that some architecture that inspired by the nature for different prospective some need strength so the choose internal structure of the tree, some architect need best outer look so the go bionic design some automobile or aviation vehicles need more fuel efficiency so developed the different accessories like vortex generator the inspired by big fish, diffuser and other thighs. this paper also shown mythology of bionic design different-different step of bio design and also production of bionic design in mechanical field. the processes that help produce bionic components.

\section{REFERENCES}

1. Luriie E (2014), Luke Journal of Biotechnology Advances, (pp.1494-1505).

2. Lothar W, Isenmann R, Moehrle M.G. 2011 Procedia Engineering, (pp. 620-632).

3. Shu L.H, Ueda K., Chiu I, Cheong H (2011), CIRP Annals - Manufacturing Technology, (p.673-693)

4. Ruszaj A (2015), Advances in Manufacturing Sci. and Tech.:( pp. 5-22).

5. ArticleSourcehttps://www.extremetech.com/extreme/224363scientists-create-touch-sensitive-bionic-finger.

Publication Date: March 9, 2016

6. Article Source-http://hargaa.id. Publication Date: September 9, 2016

7. Article Source- limbionicsofsanford.com/the-first-fullybionic-leg-available Publication Date: September 16, 2013

8. S.Gao,B Zhang,,J.Sun (2019)Hindawi Applied Bionics and Biomechanics,:( pp.1-19) 
9. Ruszaj A (2015), Advances in Manufacturing Science and Technology, (pp. 5-22).

10. Article Source- http://www.techietonics.com/robotonics/biomimicry-bionic-ants-for-futures-factoryworkers.html, Publication Date: April 1, 2015

11. Sadri M., Kavandi M., Jozepiri A, Teimouri S, Abbasi F. (2014), Research Journal Recent Science, (pp. 93-98).

12. Shahbazi H., Montazer F (2011), International Conference on Nanotechnology and Biosensors, (pp 106-110).

13. Denis A, Coelho, Carlos A., Versos M (2010), International Conference Design, (pp. 40-45).

14. Yin J.,.Yang W(2017), IPO Conferance Series Materials Science and Engineering,( pp.1-5).

15. Lippert R.B, Lachmayer (2016), International Design Conference, (pp. 331-340).

16. Ansari Md J, Nguyen D.S., Park H.S(2019), MDPI, (pp. 1-18).

17. Neugebauer R., Wabner M, Ihlenfeldt S., Frieb U., Schneider F., Schubert F, (2012), 45th CIRP Conference on Manufacturing Systems: (pp.561566). 